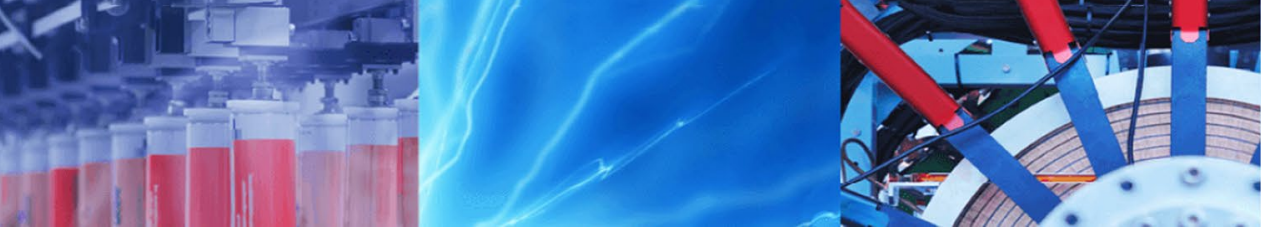

Research Article

\title{
The study of adsorption efficiency of rice husk ash for removal of phenol from wastewater with low initial phenol concentration
}

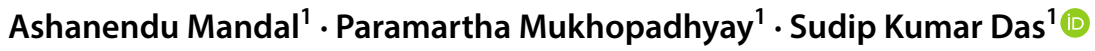

(c) Springer Nature Switzerland AG 2019

\begin{abstract}
This research work aimed to assess the adsorption efficiency of rice husk ash for removal of phenol from wastewater. The authors studied the morphology and characterization of rice husk ash using SEM, FTIR, XRD and BET analyzers and carried out the batch experiments to evaluate the removal percentage of phenol with variation of $\mathrm{pH}(3-11)$, adsorption time (30-270 $\mathrm{min})$, adsorbent dose $(0.5-4.0 \mathrm{gm} / \mathrm{L})$, phenol concentration $(5-20 \mathrm{mg} / \mathrm{L})$ and temperature $\left(25-35^{\circ} \mathrm{C}\right)$. It was observed that the maximum removal reached as high as $95 \%$. The testing of kinetic models showed that the secondorder model was better than the first-order model. Elovich model showed that the adsorption process was chemical, Reichenberg model showed that adsorption occurred because of film diffusion, Furusawa and Smith model showed that phenol moved faster from bulk to solid stage, Boyd model indicated that the process supported chemisorptions, and Fick's model implied that film and intraparticle diffusion took $45 \mathrm{~min}$ and $135 \mathrm{~min}$, respectively. Testing of isotherm models indicated that Langmuir, Freundlich and Temkin models were all supportive of equilibrium data. The DubininRadushkevich isotherm indicated that the process was explained by feeble physical adsorption. The isothermal study indicated that the process was random, endothermic and spontaneous. Although some studies had been done for removal of phenol using rice husk ash in the past, this research had covered the extensive works on the characterization of the adsorbent, extent of phenol removal with the variation of several process variables, and testing of several models in the areas of kinetics, isotherms, and thermodynamics. Further, the novelty of this research was that the experiments were carried out for treatment of wastewater exclusively with low initial phenol concentrations so that the results can be effectively applied in several small- and medium-scale industries at lesser costs, particularly in the Third World countries.
\end{abstract}

Keywords Adsorption · Phenol · Rice husk ash · Freundlich isotherm · Wastewater

\section{Introduction}

The phenol and its derivatives usually get introduced in the environment when the industrial effluents from the crude oil refinery, coal tar, plastic, disinfectant, rubber proofing, steel and pharmaceutical plants are discharged into surface water [11]. Some amounts of phenols are also released into the surface water when the domestic wastewater and agricultural runoff get mixed with the surface water. The content of phenols in such industrial, domestic and agricultural wastewaters may vary from 1 to $6800 \mathrm{mg} / \mathrm{L}$ [5].

Phenols and its derivatives are environmental pollutants of great concern because of toxicity. The health impacts caused by exposure to phenols mainly vary by the quantum of phenol and its duration. Phenol exposure to human is one of the dangers in the wastewater of any refinery because phenol is highly toxic even at low concentration [30]. The exposure to phenol on human is also common because it is available in several consumer products including gargles, mouthwash, lozenges

Sudip Kumar Das, drsudipkdas@vsnl.net; Ashanendu Mandal, ashanendumandal@gmail.com; Paramartha Mukhopadhyay, mparamartha@yahoo.co.in | ${ }^{1}$ Chemical Engineering Department, University of Calcutta, Kolkata 700009, India.

SN Applied Sciences (2019) 1:192 | https://doi.org/10.1007/s42452-019-0203-3

Received: 15 November 2018 / Accepted: 21 January 2019 / Published online: 31 January 2019 
and creams. Inhalation, dermal and oral routes are also common ways of exposure. There are unusual cases of acute respiratory and acute renal failure following the accidental overdose of phenol [16]. The toxicity of phenol results in various chronic human problems like difficulty in swallowing, vomiting, kidney damage, anorexia, fainting, liver damage, headache and common mental diseases. The phenols also have several bad effects on the environment like impacts on soil due to the decrease in porosity and flocculation, impacts on plants due to reduced germination of seeds and impacts on groundwater due to seeping of hazardous phenol through the soil [24]. The preventive measure against the exposure of phenols through surface discharge is therefore considered in this study to save the environment and human lives.

The Environmental Protection Agency (EPA), the USA has included phenols in the list of priority pollutants and has considered peak phenol value of $1 \mathrm{mg} / \mathrm{L}$ in the runoff of surface discharge. According to the regulations of Ministry of Environment, Forests and Climate Change (MOEFCC) of India, the maximum permissible limit of phenol in the discharge of industries is also considered at $1 \mathrm{mg} / \mathrm{Lin}$ line with the EPA standard [13]. The World Health Organization (WHO) has laid down the allowable value of $0.001 \mathrm{mg} / \mathrm{L}$ in the potable water. Therefore, it is required for phenol removal from industrial, domestic and agricultural wastewaters to bring out the phenol content within the allowable limit [4].

Various removal technologies like flocculation, membrane separation, solvent extraction, oxidation, photodegradation, electro-Fenton oxidation are available in the literature [36]. However, the adsorption technique is found to be very popular in wastewater treatment. The phenol removal techniques through adsorption are usually classified into three categories, viz. chemical, physical and biological adsorption [18]. The chemical methods are although useful but not preferred as they typically release further toxic compounds. The biological degradation methods are also not studied; however, they are generally quite sensitive to temperature $[34,35]$. The physical adsorption methods are found to be very useful and are therefore widely used in the industry. However, physical adsorption methods using activated carbon are discouraged due to its high cost [34, 35]. The most effective and cheapest treatment method for the removal of phenol is probably through adsorption using various natural adsorbents [12]. Many researchers are in the hunt for cheap and readily available natural adsorbents [33]. Some of the important criteria for choosing the best adsorbents, however, are the surface area, pore sizes, structural characteristics, adsorption capability, simple regeneration and numerous uses [7].
Usually, the natural materials available from the agricultural wastes are likely to be chosen as good adsorbents primarily because of their low cost [29]. In this perspective, the rice husk, which is also an agricultural waste, can be considered to be an important source for the removal of phenol from wastewater. There is no regeneration issue of rice husk since they are plentifully available at almost no cost. The porous structure and chemical stability of rice husk are also very advantageous to work as a good adsorbent for phenol removals. Another benefit of rice husk is that it can easily be transformed into rice husk ash which contains activated carbon [27].

In this research work, rice husk ash is therefore applied as the natural adsorbent to remove phenol. The vast quantities of rice husk ash are generated and dumped in rural areas of West Bengal after the uses of the rice husk as fuel. The rice husk is usually produced as a by-product from rice mills after the crushing of the paddy.

Rice husk ash predominantly contains silica, and its nature depends on the burning temperature [1]. The rice husk ash produced at the moderate temperature of $600-700{ }^{\circ} \mathrm{C}$ usually remains amorphous, while further heating makes it crystalline [22]. When the physical adsorption occurs on the silica surface, it is observed that the infrared spectrum attributed to the phenolic hydroxyl group of adsorbate is disturbed and therefore the interaction between adsorbent molecule and hydroxyl group of adsorbate becomes dominant.

$$
\mathrm{Si} \text { - O-------H - O }
$$

Analytically, it is possible to calculate the adsorption energy to confirm that the adsorption takes place on the silica surface [19].

Several studies are already available with rice husk ash for phenol removal. However, most of them are carried out with the initial phenol concentration at moderate range. Therefore, there have been concerns for some of the smalland medium-scale industries which discharge wastewater with low phenol concentration to apply such technologies. Given that this research work emphasizes treatment of wastewater with low initial phenol concentrations usually observed in small- and medium-scale industries.

\section{Materials and methods}

\subsection{Reagent and equipment}

For the adsorption process, the standard phenol having 99.99\% purity from Merck, India in crystal form was used. The other reagents like $\mathrm{NaOH}, \mathrm{HCl}$ and 4-aminoantipyrine 
from Merck, India were also used in the experiments. The equipment used in the study was spectrophotometer from Hach Co., Germany, pH meter from Hach Co., Germany, scanning electron microscope from Hitachi, Japan, X-ray powder diffraction from Bruker, Germany, and FourierTransform Infrared Spectroscopy from Thermo Fisher, the USA, and Brunauer-Emmett-Teller analyzer from NOVA, the USA. All chemicals and reagents applied in our study were arranged from a local shop in Kolkata. The equipment installed in the Chemical Engineering Department, University of Calcutta, was used for measurement of various data.

\subsubsection{Adsorbent preparation}

Rice husk ash produced from rice husk was the adsorbent which was used in our research work. Rice husk was an offshoot of rice crop, primarily cultivated in the Asian regions and mostly used as fodders for animals or sometimes thrown out as waste because of its abundance [10]. For our research work, we had collected rice husk from a rice mill near Kolkata, India. Since this rice husk contained some dust and impurities like natural fat and wax, the collected material was washed with water thoroughly. Then, it was kept in the sun for a week and burnt at $600{ }^{\circ} \mathrm{C}$ for $4 \mathrm{~h}$ to form rice husk ash. The ash was sieved, and $-44+52$-meshsized fraction was collected and stored inside desiccators.

\subsubsection{Adsorbent characterization}

The morphology and characterization of rice husk ash were studied through SEM [Model S415A, Hitachi, Japan], XRD [Germany Model D8 Advance, Bruker, Germany] and FTIR [Model Nicolet ${ }^{\mathrm{TM}} 5 \mathrm{~N}$, Thermo Fisher, USA] analyzers, and the surface area was assessed by means of BET analyzer (Model Quantachrome, NOVA 1000e, USA). The scanning electron microscopy (SEM) of rice husk ash provided the variations in microstructures because of modification during heat treatment. The SEM result of the rice husk ash is shown in Fig. 1. The result showed that rice husk ash was extremely porous with large pore sizes. The X-ray diffraction (XRD) analysis was performed for determining total amorphous nature of silica $\left(\mathrm{SiO}_{2}\right)$ present in rice husk ash, and the result is given in Fig. 2. The XRD intensity was observed as a function of Bragg angle $2 \theta$ in the angular range of $10^{\circ}-80^{\circ}$. The phase analysis was checked by comparing the values of $d$ and peak values of intensity with the available data listed in the Joint Committee of Powder Diffraction Standards [21]. The XRD pattern of rice husk ash as given in Fig. 2 indicated the presence of quartz at $2 \theta$ peaks of $22.85^{\circ}, 26.63^{\circ}$ and $42.47^{\circ}$, the presence of cristobalite at $2 \theta$ peaks of $21.91^{\circ}, 35.99^{\circ}$ and $69.50^{\circ}$ and the presence of anorthite phase at $2 \theta$ peaks of $27.91^{\circ}$ and $29.42^{\circ}$. The presence of quartz in rice husk ash prepared at

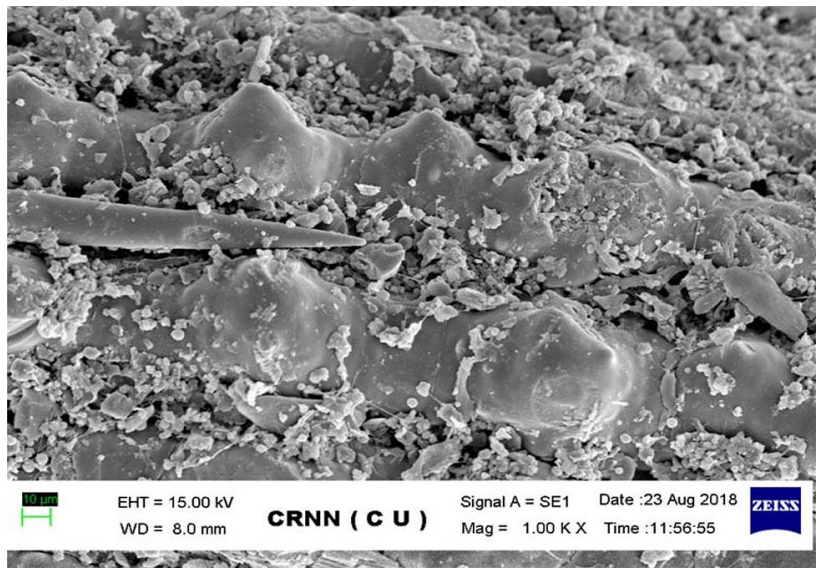

Fig. 1 SEM topography of rice husk ash

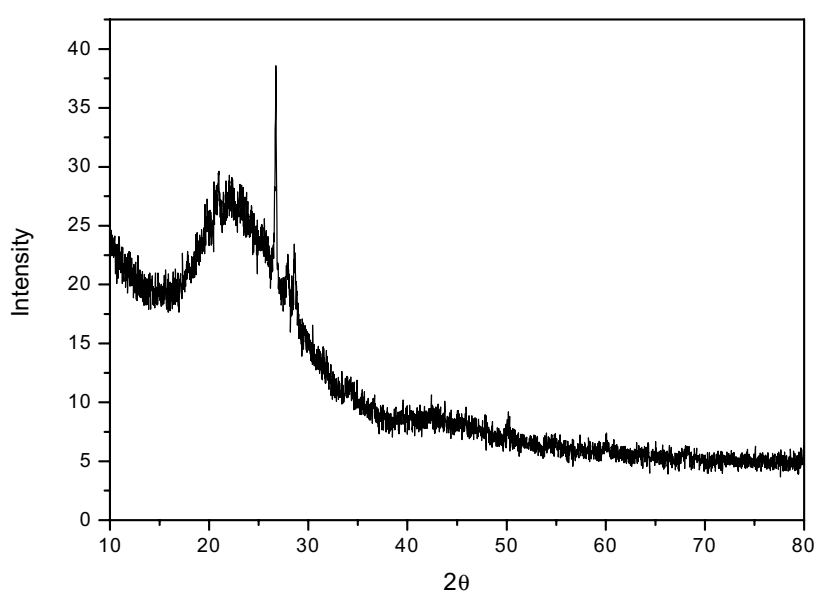

Fig. 2 Pattern of XRD of rice husk ash

$600^{\circ} \mathrm{C}$ triggered more porosity due to the evaporation of moisture content, and therefore, it would have more benefit in adsorption compared to rice husk. The presence of crystal in rice husk ash resulted in maximum surface area which again would be more advantageous for adsorption [28]. The functional groups were determined as a function of the IR spectrum using Fourier-transform infrared spectrophotometer (FTIR) for rice husk ash, and the result is given in Fig. 3. The FTIR spectrum of the rice husk ash in Fig. 3 showed broadband near $1710 \mathrm{~cm}^{-1}$ and indicated the presence of aromatic overtones of ring bends. The stretching frequency of the aromatic $\mathrm{C}=\mathrm{C}$ gave rise to the peaks at $1582 \mathrm{~cm}^{-1}$. The peak at $1093 \mathrm{~cm}^{-1}$ specified the very strong existence of alkyl fluoride $(C-F)$, whereas the peaks at 796 and $591 \mathrm{~cm}^{-1}$ indicated strong existence of alkyl chloride $(\mathrm{C}-\mathrm{Cl})$ and alkyl bromide $(\mathrm{C}-\mathrm{Br})$. The peaks at 464 and $437 \mathrm{~cm}^{-1}$ indicated the strong presence of alkyl iodide $(C-I)$. The surface area of rice husk ash was evaluated by BET analyzer, along with the distribution of its 


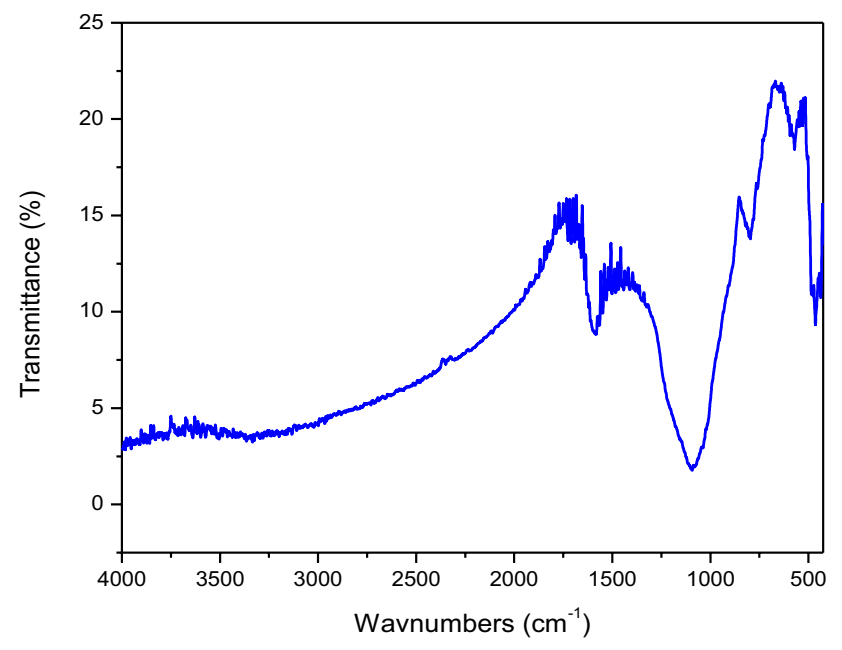

Fig. 3 FTIR spectra of rice husk ash

Table 1 Composition and physical properties of rice husk ash

\begin{tabular}{ll}
\hline Constituent & $\%$ by \\
& weight
\end{tabular}

(\%)

\section{Composition}

Loss on ignition $\quad 12.3$

$\mathrm{Fe}_{2} \mathrm{O}_{3} \quad 0.6$

$\mathrm{Al}_{2} \mathrm{O}_{3} \quad 0.2$

$\mathrm{CaO}-1.5$

$\mathrm{MgO} \quad 0.5$

$\mathrm{SiO}_{2} \quad 84.4$

$\mathrm{Na}_{2} \mathrm{O} \quad 0.3$

$\mathrm{K}_{2} \mathrm{O} \quad 0.2$

Physical properties

Bulk density $\left(\mathrm{gm} / \mathrm{cm}^{3}\right) \quad 0.96$

BET surface area $\left(\mathrm{m}^{2} / \mathrm{g}\right) \quad 57.5$

pore sizes. The results indicated that the adsorbent had honeycombed microstructure with high surface area. The surface area was estimated to be $57.5 \mathrm{~m}^{2} / \mathrm{g}$. The composition and physical properties of rice husk ash are shown in Table 1 [2].

\subsubsection{Adsorbate preparation}

Aqueous phenol solution was the adsorbate which was used in our research work. Initially, $500 \mathrm{~mL}$ of stock solution of aqueous phenol was prepared by mixing $0.5 \mathrm{gm}$ of phenol (Merck, Germany) in deionized water. The concentration of this solution was $1000 \mathrm{mg} / \mathrm{L}$ (1000 ppm). The variations of phenol concentration were carried out by dilution with distilled water, and their concentrations during the adsorption process were measured using spectrophotometer (DR 5000 Hach Co. Germany) by adding 4-aminoantipyrine. The $\mathrm{pH}$ was calculated using a $\mathrm{pH}$ meter (Model Multi 304i, Hach Co., Germany).

\subsection{Adsorption experiments-batch studies}

The studies were performed for assessing the adsorption efficiency of the phenol from its aqueous solution using rice husk ash. The experiments were carried out with the variation of process variable like initial phenol concentration, $\mathrm{pH}$, contact time, temperature, etc. [34, 35]. The aqueous phenol solution (100 mL) was taken inside $250 \mathrm{~mL}$ stopper conical flasks. Dilution by adding distilled water was made as per the desired concentration of 5, 10, 15 and $20 \mathrm{mg} / \mathrm{L}$. The $\mathrm{pH}$ was changed from 3 to 11 by using $\mathrm{NaOH}$ and $\mathrm{HCl}$. The necessary amount of rice husk ash from 0.5 to $4.0 \mathrm{gm} / \mathrm{L}$ were mixed, and the solution was shaken from 30 to $270 \mathrm{~min}$ in the electrically thermostatic shaker with 120 strokes per minute. The experiments were performed at temperatures $25^{\circ} \mathrm{C}, 30^{\circ} \mathrm{C}$, and $35^{\circ} \mathrm{C}$, respectively. At the end of specific contact time, the residue was filtered out while filtrate was examined for residual phenol concentration in the spectrophotometer [6]. All the experiments were performed in triplicate to check reproducibility, and the average was used for better accuracy.

The percentage of phenol removal is derived from Eq. (1).

$\%$ removal of phenol $=\frac{\left(C_{0}-C_{t}\right)}{C_{0}} \times 100 \%$

where $C_{0}$ and $C_{t}$ are phenol concentrations initially and at any given time $(\mathrm{mg} / \mathrm{L})$, respectively.

The amount of phenol adsorbed per unit quantity of rice husk ash is derived from Eq. (2).

$q_{t}=\frac{\left(C_{0}-C_{t}\right)}{m_{\mathrm{s}}}$

where $q_{t}$ is phenol quantity adsorbed per unit weight of rice husk ash at any given time $(\mathrm{mg} / \mathrm{g})$ and $m_{\mathrm{s}}$ is the amount of rice husk ash added in gram ( $\mathrm{gm} / \mathrm{L})$. The experiments were carried out with the various operating parameters, e.g., pH, contact time, adsorbent dose, initial phenol concentration and temperature. 


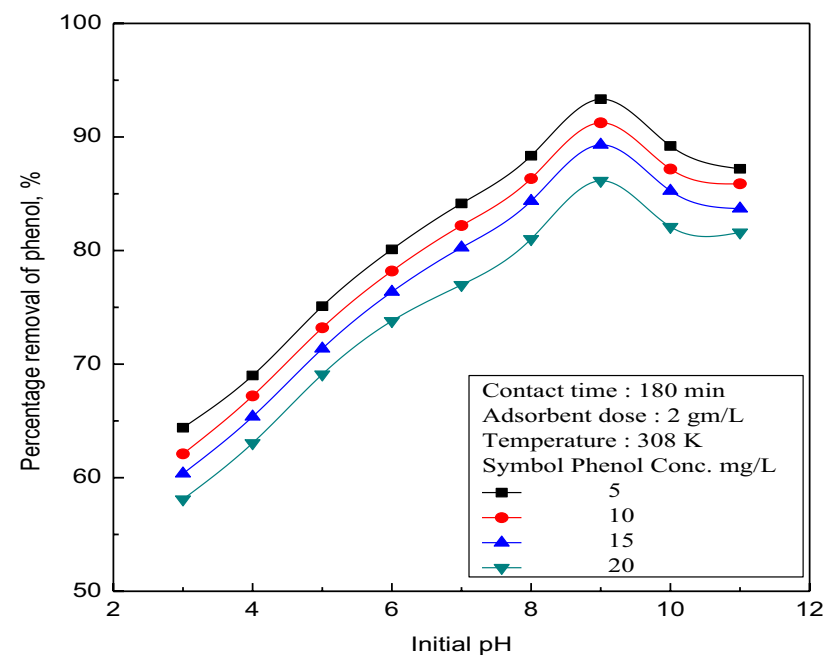

Fig. 4 Percentage removal of phenol versus $\mathrm{pH}$

\section{Results and discussion}

\subsection{Variation of $\mathrm{pH}$}

The $\mathrm{pH}$ was expected to be a considerable factor since it affects adsorption [25]. Therefore, the experiment was carried out with the variation of $\mathrm{pH}(3-11)$ at constant initial phenol concentration of $5 \mathrm{mg} / \mathrm{L}$, at constant adsorbent dosage of $2 \mathrm{gm} / \mathrm{L}$ and at constant temperature of $35^{\circ} \mathrm{C}$ for $180 \mathrm{~min}$ and was repeated in the similar way with the change of initial phenol concentration $(5-20 \mathrm{mg} / \mathrm{L})$. The plot of percentage removal of phenol versus $\mathrm{pH}$ in Fig. 4 showed that the percentage increased with the rise of $\mathrm{pH}$ from 3 to 9 . However, with the further rise in $\mathrm{pH}$, the removal efficiency decreased significantly. This observation was found irrespective of the initial phenol concentration. This phenomenon could be attributed to the amphoteric properties of the rice husk ash against the variation of $\mathrm{pH}$. At low $\mathrm{pH}$ values, phenol removal was less due to the existence of the $\mathrm{H}^{+}$ions suppressing ionization of phenol, whereas in high $\mathrm{pH}$ values, the phenol removal was high due to the existence of the $\mathrm{OH}^{-}$ions preventing uptake of phenolate ions. The lower phenol removal at further higher $\mathrm{pH}$ values might be due to the competition between the $\mathrm{OH}^{-}$ions and phenolate anions. In this research work, the point of zero charge $\left(\mathrm{pH}_{\mathrm{pzc}}\right)$ was measured by using the salt addition method [37] and was found to be 7.61. Therefore, it supported the general concept that the adsorption of phenol is superior at $\mathrm{pH}>\mathrm{pH}_{\mathrm{pzc}}$.

\subsection{Variation of contact time}

The experiment was carried out with the variation of contact time (30-270 min) at a constant $\mathrm{pH}$ of 9 , at a

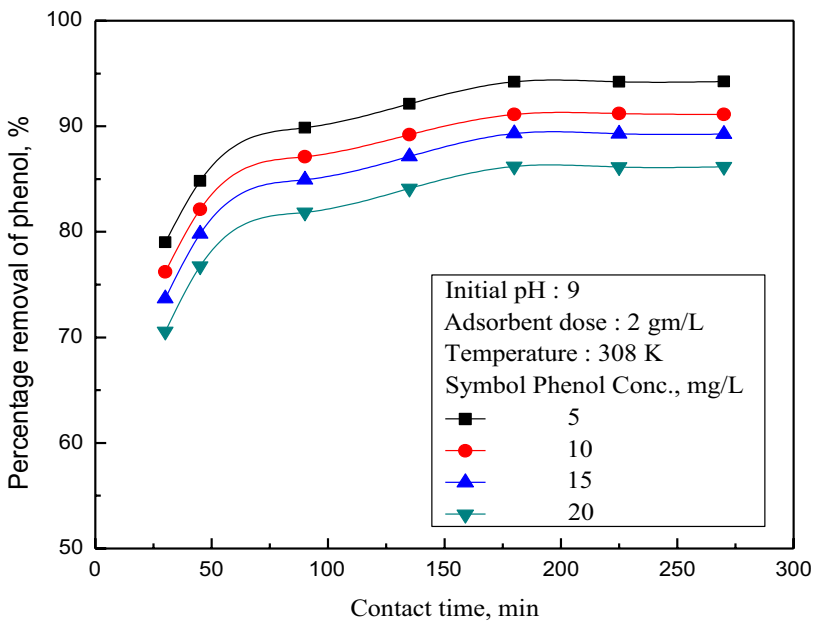

Fig. 5 Percentage removal of phenol versus contact time

constant initial phenol concentration of $5 \mathrm{mg} / \mathrm{L}$, at constant adsorbent dosage of $2 \mathrm{gm} / \mathrm{L}$ and at constant temperature of $35^{\circ} \mathrm{C}$ and was repeated in the similar way with the change of initial phenol concentration $(5-20 \mathrm{mg} / \mathrm{L})$. The plot of percentage removal of phenol versus adsorption time in Fig. 5 indicated that the efficiency was quite high in the beginning and then the equilibrium reached at $180 \mathrm{~min}$. The faster adsorption at an initial period could be endorsed to the augmented number of the vacant sites on rice husk ash existing at the original phase [40]. It might be assigned that a tendency to reach equilibrium after a specific time occurred due to three consecutive mass transfer steps. The first one was film diffusion which meant solute migrated through the solution. The second one was pore diffusion which implied the solute moved from surface to interior and lastly the solute was adsorbed at the interior.

\subsection{Variation of adsorbent dose}

The experiment was carried out with the variation of adsorbent dosage $(0.5-4 \mathrm{gm} / \mathrm{L})$ at a constant $\mathrm{pH}$ of 9 and at a constant initial phenol concentration of $5 \mathrm{mg} / \mathrm{L}$, at constant temperature $35^{\circ} \mathrm{C}$ for $180 \mathrm{~min}$ and was repeated in the similar way with the change of initial phenol concentration $(5-20 \mathrm{mg} / \mathrm{L})$. The plot of percentage removal of phenol versus adsorbent dose in Fig. 6 represented the equilibrium condition with the adsorption dose of $2 \mathrm{gm} / \mathrm{L}$. The phenomenon suggested that the removal efficiency increased rapidly at first due to more surface area and additional adsorption sites and then remained steady due to reaching saturation or equilibrium which was compatible with the results observed in the isotherm study. 


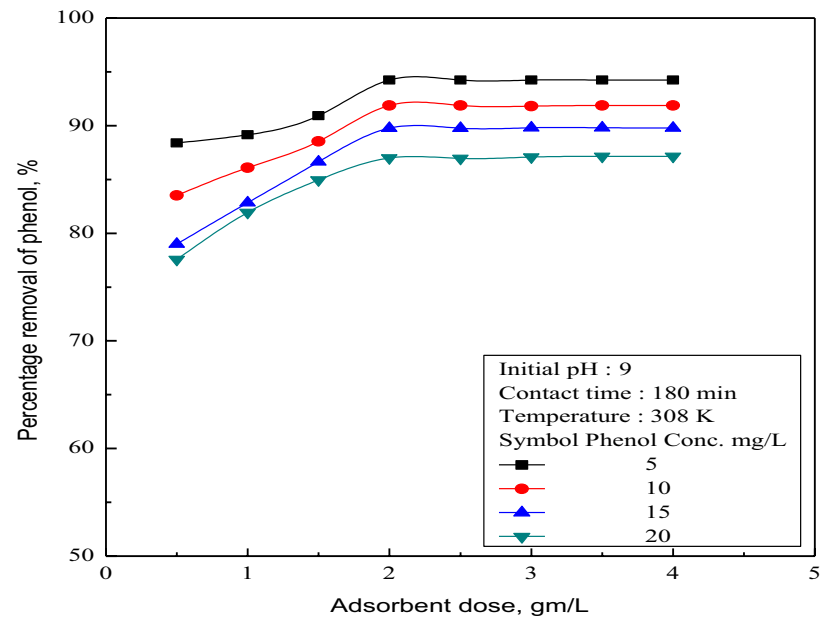

Fig. 6 Percentage removal of phenol versus adsorbent dose

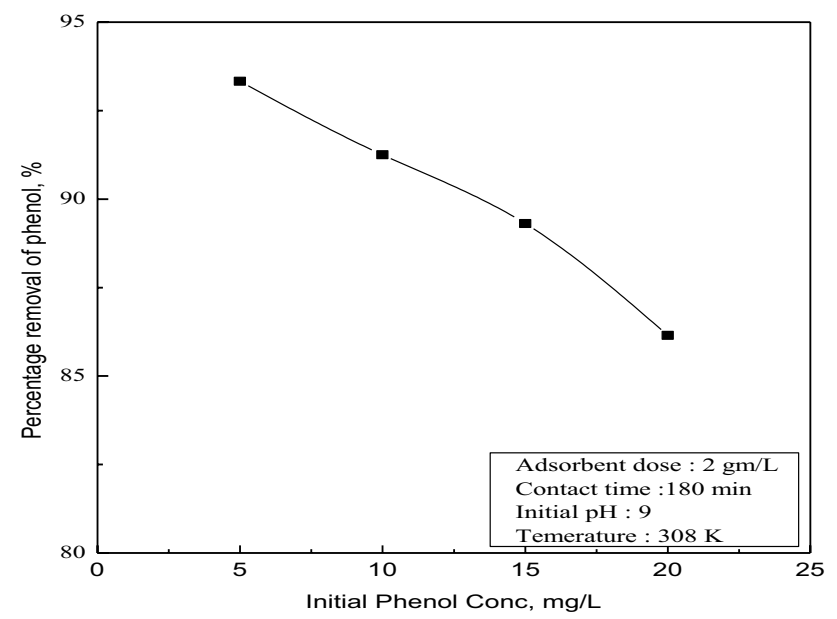

Fig. 7 Percentage removal of phenol versus initial phenol concentration

\subsection{Variation of initial phenol concentration}

In our investigation, we had experimented with the variation of initial phenol concentration of 5, 10, 15 and $20 \mathrm{mg} / \mathrm{L}$, and for each experiment, removal percentage of phenol was studied at constant pH (9), constant time (180 min), constant adsorbent quantity $(2 \mathrm{gm} / \mathrm{L}$ ) and constant temperature $\left(35^{\circ} \mathrm{C}\right)$. It was evident from Fig. 7 that at constant $\mathrm{pH}$ of 9 , constant time of $180 \mathrm{~min}$, constant dose of $2 \mathrm{gm} / \mathrm{L}$ and the constant temperature of $35^{\circ} \mathrm{C}$, the adsorption efficiency decreased with rising of initial phenol concentration. At high phenol concentration, the total adsorption sites were inadequate due to the accumulation of the phenol particles on the adsorbent surface, thus causing in the reduction of removal percentage of phenol [14].

\subsection{Variation of temperature}

The experiment was carried out with the variation of temperature $\left(25-35^{\circ} \mathrm{C}\right)$ at a constant $\mathrm{pH}$ of 9 , at a constant initial phenol concentration of $5 \mathrm{mg} / \mathrm{L}$ and at a constant adsorbent dose of $2 \mathrm{gm} / \mathrm{L}$ for $180 \mathrm{~min}$ and was repeated in the similar way with the change of initial phenol concentration $(5-20 \mathrm{mg} / \mathrm{L})$. The plot of percentage removal of phenol versus temperature in Fig. 8 represented that percentage increased with the increase in temperature from 25 to $35^{\circ} \mathrm{C}$, indicating higher chemical interaction of the adsorbate with surface functionality of the rice husk ash. This result suggested that the adsorption process of phenol by rice husk ash was a temperature-dependent process and since the extent of adsorption increased with the rise in temperature, the process would be endothermic.

\subsection{Kinetic study}

The analysis of the experimental data concerning the kinetic models facilitates to study the adsorption rate and to predict the information about adsorbent/adsorbate interaction, i.e., physisorption or chemisorption. In this research work, seven different kinetic models were tested such as the pseudo-first-order, the pseudo-second-order, the Elovich, the Boyd, the Reichenberg, the Fick, and the Furusawa and Smith models.

\subsubsection{Pseudo-first-order model}

This model is used by Lagergren [23] and expressed in Eq. (3).

$\log \left(q_{\mathrm{e}}-q_{t}\right)=\log q_{\mathrm{e}}-\frac{K_{\mathrm{ad}} t}{2.303}$

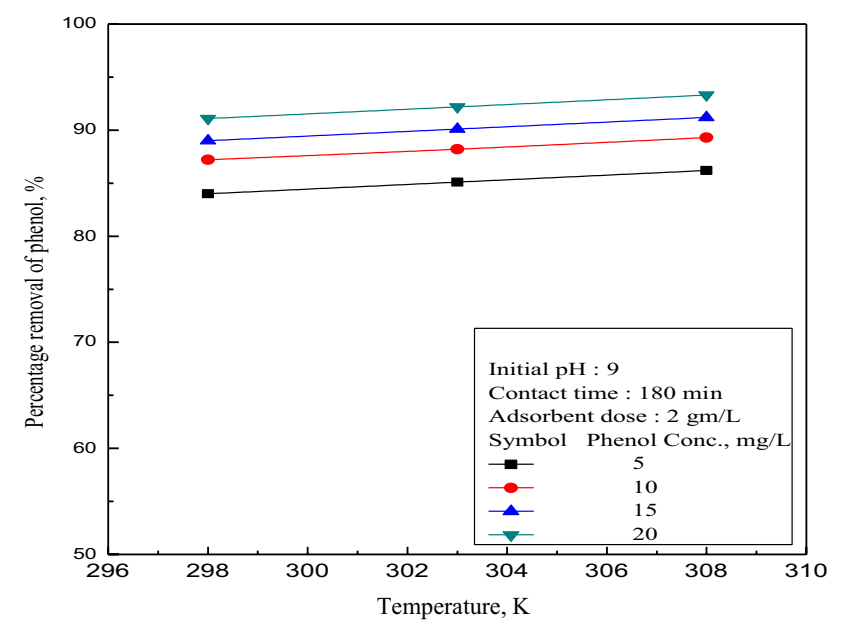

Fig. 8 Percentage removal of phenol versus adsorption temperature 


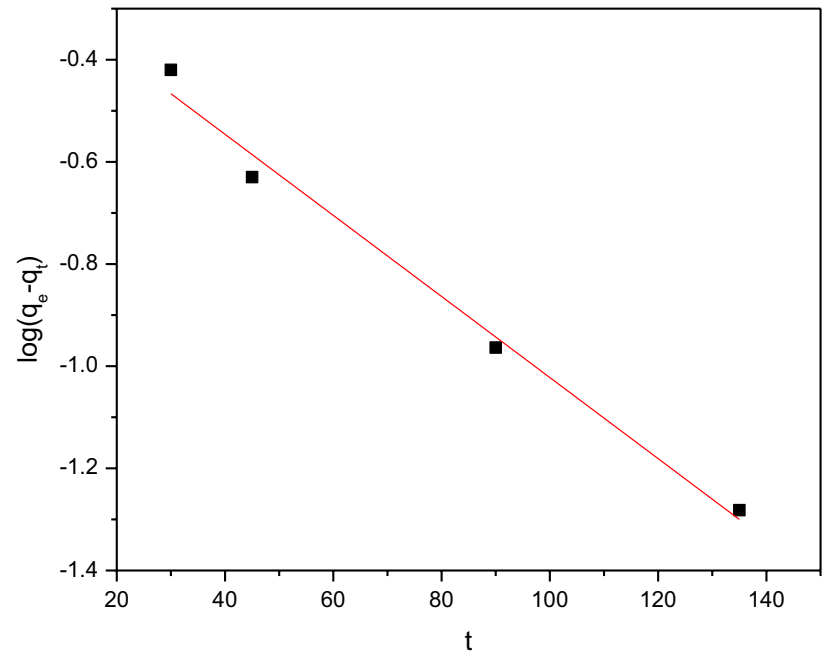

Fig. 9 Kinetic first-order model

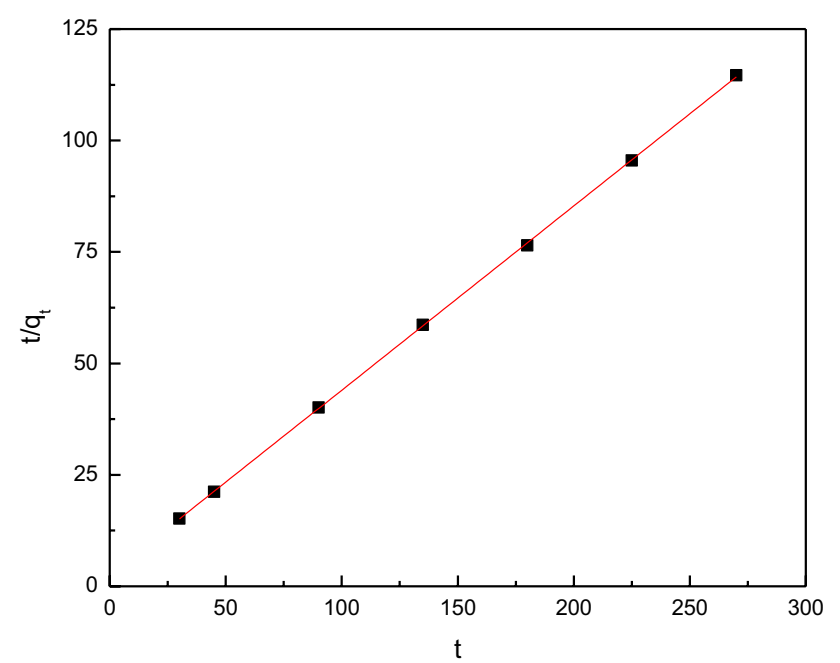

Fig. 10 Kinetic second-order model

where $q_{\mathrm{e}}$ and $q_{t}$ denote the quantity of phenol adsorbed $(\mathrm{mg} / \mathrm{g})$ at the equilibrium and at any given time, and $K_{\mathrm{ad}}$ is pseudo-first-order rate constant $\left(\mathrm{min}^{-1}\right)$. From the graph of $\log \left(q_{\mathrm{e}}-q_{t}\right)$ against $t$ as shown in Fig. 9 , it was observed that the curve was almost linear [37]. The correlation coefficient $\left(r^{2}\right)$ and $K_{\text {ad }}$ were found to be 0.98295 and 0.01829 $\left(\mathrm{min}^{-1}\right)$, respectively. The support of the pseudo-first-order model represents that the adsorption process is physisorption and the adsorbent particles are homogeneous [9].

\subsubsection{Pseudo-second-order model}

This model is expressed in Eq. (4).

$\frac{t}{q_{t}}=\frac{1}{K^{\prime} q_{\mathrm{e}}^{2}}+\frac{1}{q_{\mathrm{e}}} t$

where $K^{\prime}$ is the pseudo-second-order rate constant ( $\mathrm{gm} /$ $\mathrm{mg} \mathrm{min}$ ). From the graph of $\frac{t}{q_{t}}$ versus $t$ as shown in Fig. 10, it was observed that the curve was almost linear with the correlation coefficient $\left(r^{2}\right)$ as 0.99991 and $K^{\prime}$ thus calculated from the slope was found to be $0.06321 \mathrm{gm} / \mathrm{mg} \mathrm{min}$. The support of the pseudo-second-order model represents that the adsorption process is chemisorption and the adsorbent particles are heterogeneous [9].

Table 2 shows good conformity between experimental and calculated q values for pseudo-second-order kinetics, and therefore, the pseudo-second-order kinetics was more relevant. This confirmed that the adsorbent particles were heterogeneous and the adsorption process was chemical.

\subsubsection{Elovich model}

This model is usually applicable to chemisorptions and is expressed in Eq. (5).

$q_{t}=\frac{1}{b_{1}} \ln \left(a_{1} b_{1}\right)+\frac{1}{b_{1}} \ln \left(t+t_{0}\right)$

where $a_{1}, b_{1}$ and $t_{0}\left(=\frac{1}{a_{1} b_{1}}\right)$ are Elovich constants. The graph $q_{t}$ against $\ln t$ as shown in Fig. 11 showed the high correlation coefficient $\left(r^{2}\right)$ of 0.96314 , and therefore, it indicated that the process of the adsorption was chemical [20].

\subsubsection{Boyd model}

The Boyd et al. [8] model states that the diffusion rates in the adsorption process form Eq. (6).

$F(t)=1-\frac{6}{\pi^{2}} \sum_{n_{1}=1}^{\alpha} \frac{1}{n_{1}^{2}} \exp \left(-\frac{D_{\mathrm{e}} t \pi^{2} n_{1}^{2}}{R_{\mathrm{a}}^{2}}\right)$

Assuming the adsorbent as spherical, the Vermeulen approximates it as in Eq. (7).

$\ln \left[\frac{1}{1-F^{2}(t)}\right]=\frac{\pi^{2}}{R_{\mathrm{a}}^{2}} D_{\mathrm{e}} t$
Table 2 Pseudo-first-order and pseudo-second-order rate constants and $q_{\mathrm{e}}$ values

\begin{tabular}{|c|c|c|c|c|c|c|c|}
\hline \multirow[t]{2}{*}{$C_{\mathrm{o}}(\mathrm{mg} / \mathrm{L})$} & \multirow[t]{2}{*}{$q_{\mathrm{e}, \exp }(\mathrm{mg} / \mathrm{g})$} & \multicolumn{3}{|c|}{ Lagergren first order } & \multicolumn{3}{|c|}{ Pseudo second order } \\
\hline & & $K_{\mathrm{ad}}(1 / \mathrm{min})$ & $q_{\mathrm{e}, \mathrm{cal}}(\mathrm{mg} / \mathrm{g})$ & $r^{2}$ & $K^{\prime}(\mathrm{gm} / \mathrm{mg} \mathrm{min})$ & $q_{\mathrm{e}, \mathrm{cal}}(\mathrm{mg} / \mathrm{g})$ & $r^{2}$ \\
\hline 5 & 2.355 & 0.01829 & 0.591 & 0.98295 & 0.06321 & 2.421 & 0.99991 \\
\hline
\end{tabular}




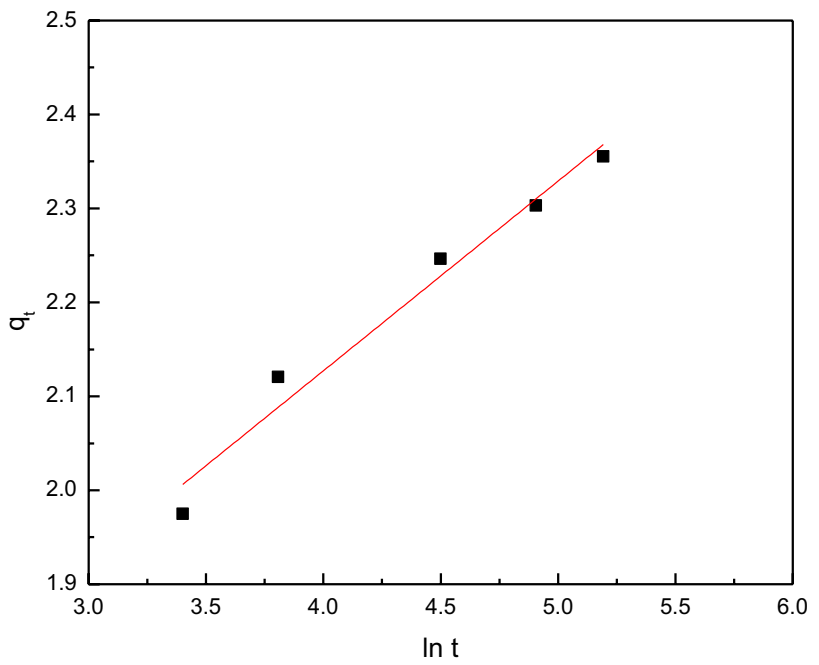

Fig. 11 Elovich model

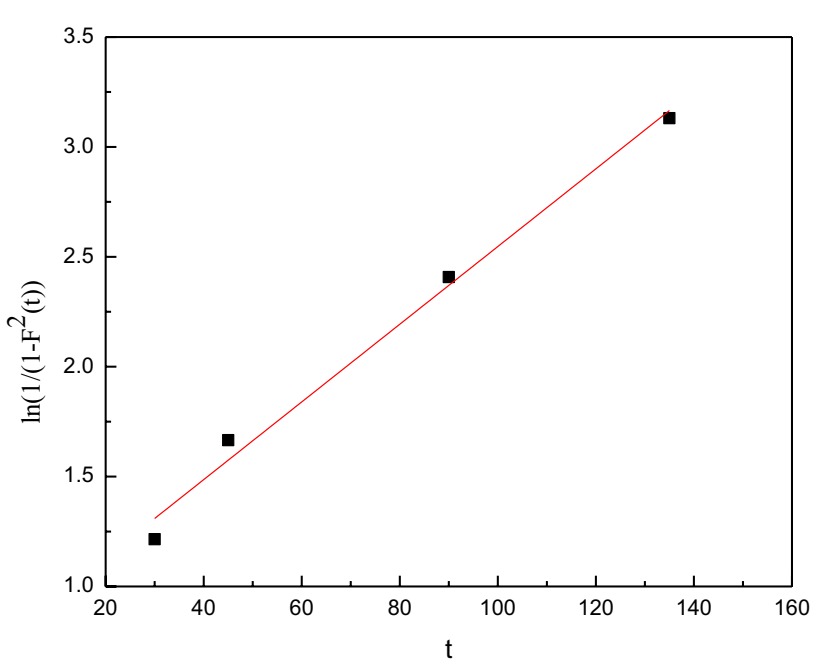

Fig. 12 Boyd model

where $R_{\mathrm{a}}$ is the radius of rice husk ash particles $(\mathrm{m})$, and $D_{\mathrm{e}}$ is an effective diffusion coefficient of the adsorbate in the adsorbent phase $\left(\mathrm{m}^{2} / \mathrm{s}\right)$. The graph of $\ln \left[\frac{1}{1-F^{2}(t)}\right]$ with $t$ as shown in Fig. 12 was best fitted to a straight line with the correlation coefficient $\left(r^{2}\right)$ of 0.98603 with a slope of $\frac{\pi^{2}}{R_{a}^{2}} D_{e} t$. The value of diffusion coefficient $\left(D_{\mathrm{e}}\right)$ was calculated as $1.182 \times 10^{-9} \mathrm{~m}^{2} / \mathrm{s}$. Since the value of $D_{\mathrm{e}}$ fell in the range of $10^{-9}$ to $10^{-17} \mathrm{~m}^{2} / \mathrm{s}$, it supported chemisorptions system [38].

\subsubsection{Reichenberg model}

This model [32] is usually applicable to film diffusion inside micropores and is expressed in Eq. (8).
$F(t)=\left(1-\frac{6}{\pi^{2}}\right) e^{-B_{t}}$

The above Equation is rewritten as in Eq. (9).

$B_{t}=-0.4977 \ln [1-F(t)]$

where $F(t)$ is a ratio of phenol adsorbed per unit of rice husk ash at any time and equilibrium, and $B_{t}$ is a timerelated constant. The graph of $B_{t}$ and $t$ as shown in Fig. 13 indicated a higher correlation coefficient $\left(r^{2}\right)$ of 0.98309 which signified that the adsorption was because of film diffusion.

\subsubsection{Fick's model}

Equation (10) developed by Adolf Fick describes the diffusion of phenol on rice husk ash surface by film or intraparticle.

$\frac{q_{t}}{q_{\alpha}}=\frac{6}{R_{\mathrm{a}}} \sqrt{\frac{D_{\mathrm{e}} t}{\pi}}$

where $q_{\alpha}$ (assumed as $q_{\mathrm{e}}$ ) is the quantity of phenol (in $\mathrm{mg}$ ) per gram of rice husk ash at equilibrium. The graph of $\frac{q_{t}}{q_{\alpha}}$ and $\sqrt{t}$ as given in Fig. 14 implied that first, second and last linear portions indicated film diffusion, intraparticle diffusion and adsorption-desorption equilibrium, respectively. Figure 14 shows that the film diffusion and intraparticle diffusion took about $45 \mathrm{~min}$ and $135 \mathrm{~min}$ and their ratio is 1:3.

\subsubsection{Furusawa and Smith model}

This model for analyzing the effect of external mass transfer on adsorption rate is explained by Eq. (11).

$\ln \left(\frac{C_{t}}{C_{0}}-\frac{1}{1+M K_{b q}}\right)=\ln \left(\frac{M K_{b q}}{1+M K_{b q}}\right)-\left(\frac{1+M K_{b q}}{M K_{b q}}\right) \beta S_{S} t$

where $C_{0}$ and $C_{t}$ are phenol concentration $(\mathrm{mg} / \mathrm{L})$ in the beginning and at any time, $M$ is the mass of rice husk ash per unit volume $(\mathrm{gm} / \mathrm{L}), \beta$ is the mass transfer coefficient $(\mathrm{cm} / \mathrm{s}), S_{\mathrm{S}}$ is the external surface area per volume $\left(\mathrm{m}^{-1}\right)$, and $K_{b q}$ is a mass transfer constant $(\mathrm{L} / \mathrm{g})$. The value of $K_{b q}$ was evaluated by multiplication of $b$ with $q_{\text {max }}$ where $b$ means Langmuir constant connected to free energy of adsorption ( $\mathrm{L} / \mathrm{mg})$ and $q_{\max }$ means the maximum adsorption capacity (mg/g), and both $b$ and $q_{\max }$ were derived from Langmuir adsorption isotherm model). The plot of $\ln \left(\frac{C_{t}}{c_{0}}-\frac{1}{1+M K_{b q}}\right)$ against $t$ as shown in Fig. 15 formed linear line with the correlation coefficient $\left(r^{2}\right)$ of 0.98329 with the slope of $\left(\frac{1+M K_{b q}}{M K_{b q}}\right) \beta S_{S}$ in linear fitting. The value of the mass transfer 
Fig. 13 Reichenberg model

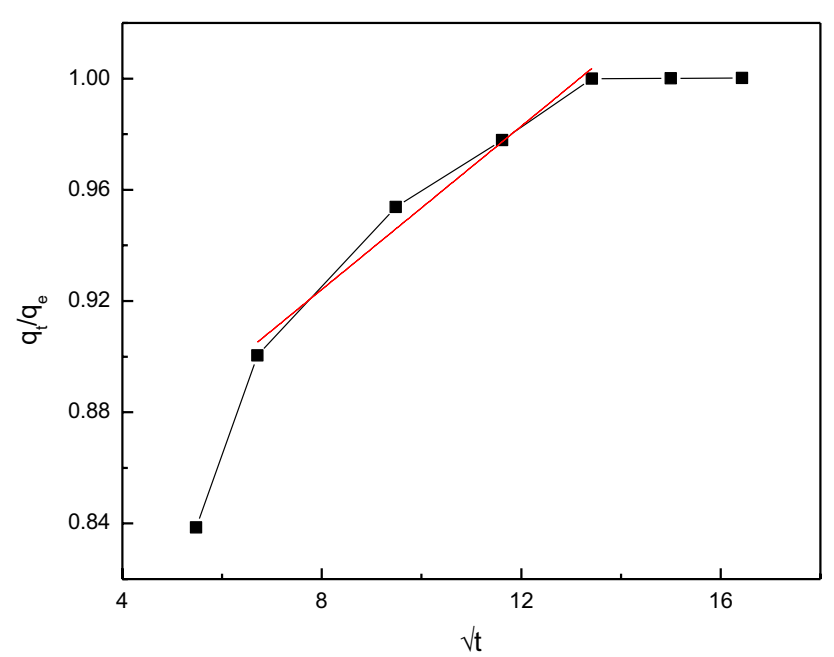

Fig. 14 Fick's model

coefficient $(\beta)$ of $5.224 \times 10^{-10}$ which was calculated using the value of the slope indicated that phenol moved faster from bulk to the solid stage.

The results of the above five statistical kinetic models tested in this research work are given in Table 3. Table 3 shows good conformity for all the models due to high correlation coefficients.

\subsection{Isothermal study}

The analysis of the experimental isotherm results was essential since it helped to develop an equation which was applied for the design purposes. Various isotherm models were available in the literature to analyze the
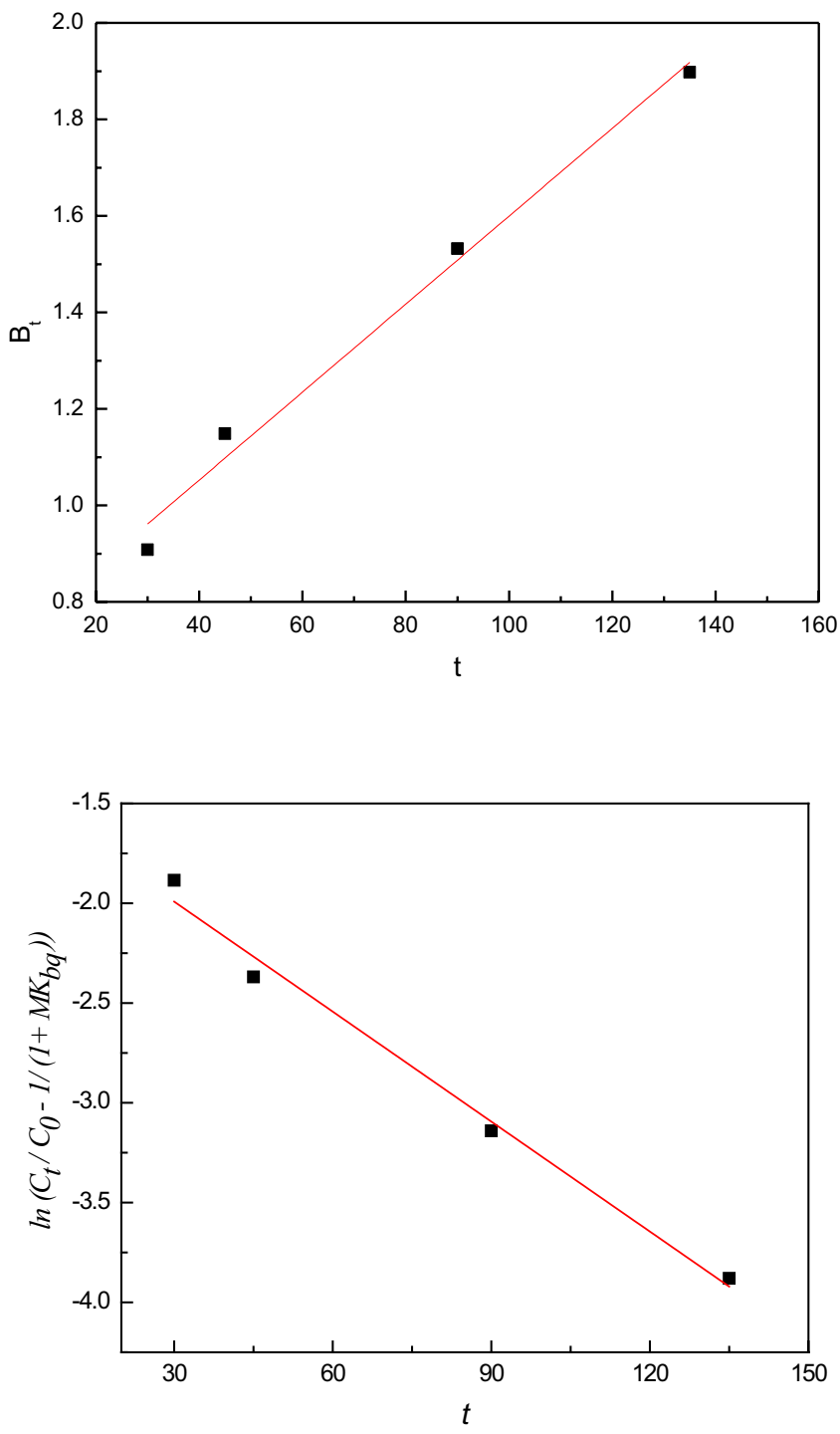

Fig. 15 Furusawa and Smith Model

experimental isotherm data, of which Langmuir, Freundlich, Temkin and Dubinin-Radushkevich models were used in this research work.

\subsubsection{Langmuir isotherm}

This model is given in Eq. (12).

$\frac{C_{\mathrm{e}}}{q_{\mathrm{e}}}=\frac{1}{q_{\max } b}+\frac{C_{\mathrm{e}}}{q_{\max }}$

where $C_{\mathrm{e}}$ is phenol concentration in solution at the equilibrium (mg/L), $q_{\mathrm{e}}$ is quantity of adsorbate $(\mathrm{mg})$ adsorbed per unit of the adsorbent $(\mathrm{gm})$ at the equilibrium, $q_{\max }$ $(\mathrm{mg} / \mathrm{g})$ and $b$ are Langmuir constants linked to the maximum adsorption capacity ( $\mathrm{mg}$ of solute per gm of the 
Table 3 Kinetic model results

\begin{tabular}{|c|c|c|c|}
\hline Kinetic model & Model equation & $\begin{array}{l}\text { Correlation } \\
\text { coefficient }\end{array}$ & Result \\
\hline Elovich model & $q_{t}=\frac{1}{b_{1}} \ln \left(a_{1} b_{1}\right)+\frac{1}{b_{1}} \ln \left(t+t_{0}\right)$ & 0.96314 & Adsorption is chemical \\
\hline Boyd model & $\ln \left[\frac{1}{1-F^{2}(t)}\right]=\frac{\pi^{2}}{R_{\mathrm{a}}^{2}} D_{\mathrm{e}} t$ & 0.98603 & Supports for chemisorption \\
\hline Reichenberg model & $B_{t}=-0.4977 \ln [1-F(t)]$ & 0.98309 & Adsorption is of film diffusion. \\
\hline Fick model & $\frac{q_{\mathrm{t}}}{q_{\alpha}}=\frac{6}{R_{\mathrm{a}}} \sqrt{\frac{D_{\mathrm{e}} t}{\pi}}$ & 1.0 & $\begin{array}{l}\text { The film diffusion and the intraparticle dif- } \\
\text { fusion take about } 45 \mathrm{~min} \text { and } 135 \mathrm{~min}\end{array}$ \\
\hline Furusawa and Smith model & $\ln \left(\frac{C_{t}}{C_{0}}-\frac{1}{1+M K_{b q}}\right)=\ln \left(\frac{M K_{b q}}{1+M K_{b q}}\right)-\left(\frac{1+M K_{b q}}{M K_{b q}}\right) \beta S_{S} t$ & 0.98329 & $\begin{array}{l}\text { Phenol moves faster from bulk to solid } \\
\text { stage }\end{array}$ \\
\hline
\end{tabular}

adsorbent) and the free energy of adsorption (L/mg). From the graph of $\frac{C_{\mathrm{e}}}{q_{\mathrm{e}}}$ and $C_{\mathrm{e}}$, the values of Langmuir constants $q_{\max }$ and $b$ were derived [26]. The large value of $q_{\max }$ signified that amount of phenol adsorbed per unit of rice husk ash ( $\mathrm{gm}$ ) formed a complete monolayer and the large value of $b$ signified that the strong bonding of phenol took place with rice husk ash [3]. The important characteristic of the Langmuir isotherm was evaluated in term of constant separation factor (dimensionless) for equilibrium, $R_{\mathrm{L}^{\prime}}$ which is defined by Eq. (13).

$R_{\mathrm{L}}=\frac{1}{1+b C_{0}}$

Using the value of $b$, the values of $R_{\mathrm{L}}$ at the initial phenol concentration of $5,10,15$ and $20 \mathrm{mg} / \mathrm{L}$ were calculated as $0.348,0.174,0.116$ and 0.087 , respectively. Since the values of $R_{\mathrm{L}}$ lied within 0 and 1 , the Langmuir isotherm was favorable within the experimental range [17].

\subsubsection{Freundlich isotherm}

This model is specified in Eq. (14).

$\log q_{\mathrm{e}}=\log K_{\mathrm{f}}+\frac{1}{n} \log C_{\mathrm{e}}$

where $C_{\mathrm{e}}$ is phenol concentration in solution at the equilibrium ( $\mathrm{mg} / \mathrm{L}), q_{\mathrm{e}}$ is the amount of the adsorbate $(\mathrm{mg})$ adsorbed per unit of the rice husk ash (gm) at equilibrium, and $K_{\mathrm{f}}$ and $n$ are Freundlich constants associated with adsorption capacity and adsorption strength in adsorption process, respectively. From the graph of $\log q_{\mathrm{e}}$ and $\log C_{\mathrm{e}^{\prime}}$ the Freundlich constants $K_{\mathrm{f}}$ and $\frac{1}{n}$ were derived [15]. The higher value of Freundlich constant $K_{\mathrm{f}}$ represented easy removal of phenol from the wastewater. The value of $n$ which represented the intensity of adsorption followed the limit $\left(0<\frac{1}{n}<1\right)$ and therefore signified that surface of rice husk ash was heterogeneous in nature [3].

\subsubsection{Temkin isotherm}

This model is expressed in Eq. (15).

$q_{\mathrm{e}}=B_{1} \ln K_{\mathrm{T}}+B_{1} \ln C_{\mathrm{e}}$

where $C_{\mathrm{e}}$ is phenol concentration at the equilibrium $(\mathrm{mg} / \mathrm{L}), q_{\mathrm{e}}$ is the quantity of adsorbate $(\mathrm{mg})$ adsorbed per gram of the adsorbent at the equilibrium, and $B_{1}$ and $K_{\mathrm{T}}$ are Temkin constants connected to heat of adsorption ( $\mathrm{J} /$ $\mathrm{mol})$ and equilibrium binding $(\mathrm{L} / \mathrm{g})$, respectively. The graph of $q_{\mathrm{e}}$ against $\ln C_{\mathrm{e}}$ evaluated the Temkin constants $B_{1}$ and $K_{\mathrm{T}}$. The values of $B_{1}$ and $K_{\mathrm{T}}$ signified that the adsorption process was chemical [39].

\subsubsection{Dubinin-Radushkevich model}

This model for calculation of adsorption energy is given in Eq. (16).

$\ln C_{\text {ads }}=\ln X_{\mathrm{m}}-\lambda \varepsilon^{2}$

where $C_{\mathrm{ads}}$ is quantity of phenol adsorbed onto rice husk ash surface $(\mathrm{mol} / \mathrm{g}), X_{\mathrm{m}}$ is maximum adsorption capacity $(\mathrm{mmol} / \mathrm{g}), \lambda$ is a constant for adsorption energy $\left.\left(\mathrm{mol}^{2} / \mathrm{kJ}\right)^{2}\right)$, and $\varepsilon$ is the Polanyi potential $\left(\mathrm{kJ}^{2} / \mathrm{mol}^{2}\right)$ which is calculated as $\varepsilon=R T \ln \left(1+\frac{1}{C_{\mathrm{e}}}\right)$.

The graph for $\ln C_{\text {ads }}$ with $\varepsilon^{2}$ gave a line with the correlation coefficient $\left(r^{2}\right)$ of 0.91996 from which $\lambda$ and $X_{\mathrm{m}}$ were derived as $0.10139\left(\mathrm{~mol}^{2} / \mathrm{kJ}^{2}\right)$ and $8.475 \times 10^{-5}(\mathrm{mmol} / \mathrm{g})$ respectively.

Adsorption energy is further calculated using $\varepsilon^{2}$ as in Eq. (17).

$E=\frac{1}{\sqrt{2 \lambda}}$ 
Table 4 Isotherm model parameters

\begin{tabular}{|c|c|c|c|}
\hline Kinetic model & Model equation & $\begin{array}{l}\text { Correlation } \\
\text { coefficient }\end{array}$ & Isotherm constants \\
\hline Langmuir isotherm & $\frac{c_{\mathrm{e}}}{q_{\mathrm{e}}}=\frac{1}{q_{\max ^{b}}}+\frac{C_{\mathrm{e}}}{q_{\max }}$ & 0.99494 & $\begin{array}{l}q_{\max }(\mathrm{mg} / \mathrm{g})=13.9821 \\
b(\mathrm{~L} / \mathrm{mg})=0.57524\end{array}$ \\
\hline Freundlich isotherm & $\log q_{\mathrm{e}}=\log K_{\mathrm{f}}+\frac{1}{n} \log C_{\mathrm{e}}$ & 0.98260 & $\begin{array}{l}K_{\mathrm{f}}=5.26478 \\
n=1.83268\end{array}$ \\
\hline Temkin isotherm & $q_{\mathrm{e}}=B_{1} \ln K_{\mathrm{T}}+B_{1} \ln C_{\mathrm{e}}$ & 0.98160 & $\begin{array}{l}B_{1}(\mathrm{~J} / \mathrm{mol})=2.97175 \\
K_{\mathrm{T}}(\mathrm{L} / \mathrm{g})=6.06783\end{array}$ \\
\hline $\begin{array}{l}\text { Dubinin-Radushkevich } \\
\text { isotherm }\end{array}$ & $\begin{array}{l}\ln C_{\mathrm{ads}}=\ln X_{\mathrm{m}}-\lambda \varepsilon^{2} \\
E=\frac{1}{\sqrt{2 \lambda}}\end{array}$ & 0.91996 & $\begin{array}{l}X_{\mathrm{m}}(\mathrm{mmol} / \mathrm{g})=8.475 \times 10^{-5} \\
E(\mathrm{~kJ} / \mathrm{mol})=2.2207\end{array}$ \\
\hline
\end{tabular}

Table 5 Values of $\Delta G^{\circ}, \Delta H^{\circ}$ and $\Delta S^{\circ}$

\begin{tabular}{llll}
\hline$T(\mathrm{~K})$ & $\Delta G^{\circ}(\mathrm{kJ} / \mathrm{mol})$ & $\Delta H^{\circ}(\mathrm{kJ} / \mathrm{mol})$ & $\Delta S^{\circ}(\mathrm{kJ} / \mathrm{mol} \mathrm{K})$ \\
\hline 298 & -4.04528 & 23.478 & 0.0923 \\
303 & -4.47573 & & \\
308 & -4.96923 & & \\
\hline
\end{tabular}

where $E$ means adsorption energy $(\mathrm{kJ} / \mathrm{mol})$ to adsorb $1 \mathrm{~mol}$ of phenol from its solution. Since the value of $E$ as calculated here was $2.2207 \mathrm{~kJ} / \mathrm{mol}$ and was below 8 , the adsorption was physical. However, it seemed to be weak since the value of the correlation coefficient was less.

The values of isotherm parameters as obtained from the isotherm graphs are shown in Table 4. Table 4 indicates that the Langmuir isotherm, the Freundlich isotherm and the Temkin isotherm were applicable with the experimental results because of the high correlation coefficients $\left(r^{2}\right)$ values. The monolayer adsorption capacity $\left(q_{\max }\right)$ from Langmuir isotherm model was assessed as $13.9821 \mathrm{mg} / \mathrm{g}$.

\subsection{Thermodynamic study}

The thermodynamic study was carried out to assess the feasibility of the adsorption process by evaluating the values of Gibbs free energy change, enthalpy change, and entropy change. While the Gibbs free energy change indicated whether the process was spontaneous or not, the enthalpy change suggested whether the process was endothermic or exothermic and the entropy change pointed out whether the adsorption process was physical or chemical. The Gibbs free energy, the enthalpy and the entropy are expressed in Eqs. (18) and (19), respectively.

$\Delta G^{\circ}=-R T \ln K_{\mathrm{c}}$

$\ln K_{\mathrm{c}}=-\frac{\Delta H^{\circ}}{R T}+\frac{\Delta S^{\circ}}{R}$

where $\Delta G^{\circ}$ is Gibbs free energy $(\mathrm{kJ} / \mathrm{mol}), R$ stands for ideal gas constant $0.008314 \mathrm{~kJ} / \mathrm{mol} \mathrm{K}, K_{\mathrm{c}}$ indicates equilibrium constant, $\Delta H^{\circ}$ is Enthalpy $(\mathrm{kJ} / \mathrm{mol})$, and $\Delta S^{\circ}$ is Entropy $(\mathrm{kJ} /$ $\mathrm{mol} \mathrm{K)}$. For rice husk ash, using the value of $K_{\mathrm{c}}$ in Eq. (18), the values of $\Delta G^{\circ}$ for three different temperatures at $25^{\circ} \mathrm{C}$, $30^{\circ} \mathrm{C}$ and $35^{\circ} \mathrm{C}$ were calculated. Using Eq. (19), from the graph of $\ln K_{\mathrm{c}}$ against $\frac{1}{T}$, the values of $\Delta H^{\circ}$ and $\Delta S^{\circ}$ were calculated. The values of $\Delta G^{\circ}, \Delta H^{\circ}$, and $\Delta S^{\circ}$ thus calculated are shown in Table 5. Here, the negative value of $\Delta G^{\circ}$ implied that adsorption process was feasible and spontaneous, whereas positive values of $\Delta H^{\circ}$ and $\Delta S^{\circ}$ indicated that the adsorption process was an endothermic and random with the increased degree of freedom at the solid-liquid interface. The higher values of $\Delta G^{\circ}$ at the higher temperature range $\left(25-35^{\circ} \mathrm{C}\right)$ were supportive of the experimental results which showed that the removal percentage of phenol increased with the increase in temperature. The endothermic nature of adsorption process by the positive value of $\Delta H^{\circ}$ was also supportive of the experimental results which showed that the removal percentage of phenol increased with the increase in temperature.

\section{Safe disposal of used adsorbent}

The rice husk ash which was used as an adsorbent in this research was produced from rice husk by burning at $600^{\circ} \mathrm{C}$. There is no scarcity of this adsorbent since the rice husk is abundantly available in the Asian countries at almost free of cost. Therefore, the regeneration of the adsorbent was not essential. The used adsorbent can be disposed of safely or can be reused for road filling after incineration since the toxic effect of adsorbed phenol gets destroyed through incineration.

\section{Scale-up design}

The batch adsorption process is usually designed by considering adsorption isotherm [31]. It is assumed that when phenol is mixed with $W$ mass of rice husk ash, the initial phenol concentration is decreased from $C_{0}$ to $C_{t}$ of the 
Table 6 Weight of adsorbent (gm) for different volume of phenol solution $(\mathrm{L})$

\begin{tabular}{lllll}
\hline $\begin{array}{l}\text { Volume of } \\
\text { effluent }\end{array}$ & $80 \%$ adsorption & $60 \%$ adsorption & $40 \%$ adsorption & $20 \%$ adsorption \\
\hline 2 & 1.70 & 1.27 & 0.85 & 0.42 \\
4 & 3.39 & 2.55 & 1.70 & 0.85 \\
6 & 5.09 & 3.82 & 2.55 & 1.27 \\
8 & 6.79 & 5.09 & 3.39 & 1.70 \\
10 & 8.48 & 6.36 & 4.24 & 2.12 \\
\hline
\end{tabular}

solution volume $V$ at any time wherein the phenol quantity for each gram of the rice husk ash is altered from $q_{0}$ to $q_{t}$.

At time $t=0, q_{0}=0$, mass balance Equation is expressed as Eq. (20).

$V\left(C_{0}-C_{t}\right)=W\left(q_{t}-q_{0}\right)=W q_{t}$

At equilibrium $C_{t}=C_{\mathrm{e}}$ and $q_{t}=q_{\mathrm{e}}$, Eq. (20) is modified as Eq. (21).

$\frac{W}{V}=\frac{\left(C_{0}-C_{t}\right)}{q_{t}}=\frac{\left(C_{0}-C_{t}\right)}{q_{\mathrm{e}}}$

From the testing of isotherm models, it is found that Langmuir, Freundlich and Temkin models are applicable because of high correlation coefficients. Using the Freundlich model, Eq. (21) is modified as Eq. (22).

$\frac{W}{V}=\frac{\left(C_{0}-C_{t}\right)}{q_{\mathrm{e}}}=\frac{\left(C_{0}-C_{t}\right)}{K_{\mathrm{f}}-C_{\mathrm{e}}^{1 / n}}$

Using Eq. (22), the weight of the rice husk ash (gm) required for initial phenol concentration of $5 \mathrm{mg} / \mathrm{L}$ for a different volume of aqueous phenol solution (wastewater or effluent) from 2 to $10 \mathrm{~L}$ was evaluated and is given in Table 6.

\section{Conclusion}

The efficiency of rice husk ash to adsorb phenol from wastewater was assessed in this research work. The adsorbent rice husk ash was at first characterized by using SEM, XRD, FTIR, BET analyzers. After that, the adsorption efficiencies were studied with the change of $\mathrm{pH}$, contact time, adsorbent dose, phenol concentration, and temperatures. The authors found that the equilibrium conditions were achieved at $\mathrm{pH}$ of 9, contact time of $180 \mathrm{~min}$, the adsorbent dosage of $2 \mathrm{gm}$, while at these equilibrium conditions, the efficiency reduced with the rise of the initial phenol concentration and increased with the increase in temperature. Various models had also been applied in this study. The pseudo-second-order kinetic model was superior to the first-order model. The Elovich model indicated that the adsorption process was chemical, while the Reichenberg model signified that film diffusion regulated the process. The Furusawa and Smith model for mass transfer analysis suggested that adsorbate movement from solution to solid occurred reasonably fast, while the Boyd model with the value of diffusion coefficient of $1.182 \times 10^{-9} \mathrm{~m}^{2} / \mathrm{s}$ suggested that the process was chemical. The Fick's equation described that duration of the film diffusion was around $\mathbf{4 5} \mathrm{min}$ followed by the intraparticle diffusion for the next $135 \mathrm{~min}$, and finally, the adsorption-desorption equilibrium prevailed after $180 \mathrm{~min}$. The test of isotherm models indicates that adsorption equilibrium data fit very well for Langmuir, Freundlich and Temkin models. The Dubinin-Radushkevich isotherm indicated that the process was explained by weak physical adsorption. The Gibb's free energy suggested that the process occurred spontaneously, while enthalpy and entropy pointed out that process was endothermic and random. Thus, this study concluded that rice husk ash was a cheap and appropriate adsorbent for phenol removal from wastewater. The novelty of the research was that this study was carried out for the lower range of initial phenol concentration in the wastewater, so that this research work would be suitably applicable in the small- and medium-scale industries like suburban paints, papers and hardboard manufacturing plants.

Acknowledgements The authors acknowledge Department of Science and Technology, Government of India, for the financial support for the research work. The authors also acknowledge Chemical Engineering Department, University of Calcutta, for providing all facilities during the research work.

\section{Compliance with ethical standards}

Conflict of interest The authors have no conflicts of interest to disclose.

\section{References}

1. Agarwal BM (1989) Utilization of rice husk ash. Glass Ceram Bull $36: 1-2$ 
2. Ahmaruzzaman M, Gupta VK (2011) Rice husk and its ash as lowcost adsorbents in water and wastewater treatment. Ind Eng Chem Res 50(24):13589-13613

3. Aksu Z, Yener J (2001) A comparative adsorption/absorption study of mono-chlorinated phenol onto various sorbent. Waste Manag 21:695-702

4. Almasi A, Dargahi A, Amrane A, Fazlzadeh M, Soltanian M, Hashemian A (2018) Effect of molasses addition as biodegradable material on phenol removal under anaerobic conditions. Environ Eng Manag J 17(6):1475-1482

5. Almasi A, Dargahi A, Amrane A, Fazlzadeh M, Mahmoudi $M$, Hashemian A (2014) Effect of the retention time and the phenol concentration the stabilization pond efficiency in the treatment of oil refinery wastewater. Fresenius Environ Bull 23(10a):2541-2548

6. APHA, AWWA, WEF (1998) Standard methods for examination of water and wastewater, 20th edn. APHA, New York

7. Banat FA, Al-Bashir B, Al-Asheh S, Hayajneh O (2000) Adsorption of phenol by bentonite. Environ Pollut 107:390-398

8. Boyd GE, Adamson AW, Myers LS (1947) The exchange adsorption of ions from aqueous solutions by organic zeolites. II. Kinetic. J Am Chem Soc 69:2836-2848

9. Chaudhary N, Balomajumder C, Agrawal B, Jagati VS (2014) Removal of phenol using fly ash and impregnated fly ash: an approach to equilibrium, kinetic and thermodynamic study. Sep Sci Technol 50:690-699

10. Chowdhury AK, Sarkar AD, Bandopadhyay A (2009) Rice husk ash as a low cost adsorbent for the removal of methylene blue and congo red in aqueous phases. Soil Air Water Clean 37(7):581-591

11. Dargahi A, Mohammadi M, Amirian F, Karami A, Almasi A (2017) Phenol removal from oil refinery wastewater using anaerobic stabilization pond modeling and process optimization using response surface methodology (RSM). Desalination Water Treat 87:199-208

12. Darwish NA, Halhouli KA, Al-Dhoon NM (1996) Adsorption of phenol from aqueous systems onto spent oil shale. Sep Sci Technol 31:705-714

13. Dutta NN, Borthakur S, Patil GS (2006) Phase transfer catalyzed extraction of phenolic substances from aqueous alkaline stream. Sep Sci Technol 27(11):1435-1448

14. Ekpete OA, Horsfall M, Tarawou T (2010) Potential of fluid and commercial activated carbons for phenol removal in aqueous systems. ARPN J Eng Appl Sci 5(9):39-47

15. Freundlich H (1906) Adsorption in solution. Phys Chem 57:384-410

16. Gupta S, Guha A, Divya C, Gupta AK, Finkel KW, Guntupalli JS (2008) Acute phenol poisoning: a life-threatening hazard of chronic pain relief. Clin Toxicol 46(3):250-253

17. Hall KR, Vermeylem T (1966) Pore and solid diffusion kinetics in fixed bed adsorption under constant pattern conditions. J Eng Chem Fundam 4:212-219

18. Hao OJ, Kim H, Chiang PC (2000) Decolorization of wastewater. Crit Rev Environ Sci Technol 30:449-505

19. Hertl W, Hair ML (1968) Hydrogen bonding between adsorbed gases and surface hydroxyl groups on silica. J Phys Chem ACS Publ 72:4676-4682

20. Ho YS, McKay G (2002) Application of kinetic models to the sorption of copper(II) onto peat. Adsorp Sci Technol 20(8):797-815

21. Joint Committee on Powder Diffraction Standards (1972) Anal Chem 44(12):75A-75A. https://doi.org/10.1021/ac60320a761

22. Kumar A (1993) Rice husk ash based cements, mineral admixture in cement and concrete, progress in cement and concrete, vol 4. ABI Books Pvt. Ltd. CGCRI, Kolkata, pp 342-367
23. Lagergren S (1898) Zur theorie der sogenannten adsorption geloster stoffe. Kungliga Svenska Vetenskapsakademiens. Handlingar 24:1-39

24. Lakshmi S, Harshitha M, Vaishali G, Keerthana SR, Muthappa R (2016) Studies on different methods for removal of phenol in waste water: review. Int J Sci Eng Technol Res 5(7):2488-2496

25. Lalhruaitluanga H, Jayaram K, Prasad MNV, Kumar KK (2010) Lead(II) adsorption from aqueous solutions by raw and activated charcoals of Melocanna baccifera Roxburgh (bamboo)-a comparative study. J Hazard Mater 175(1-3):311-318

26. Langmuir I (1918) The adsorption of gases on plane surfaces of glass, mica and platinum. J Am Chem Soc 40:1361-1403

27. Mahavi A, Maleki A, Eslami A (2004) Potential of rice husk and rice husk ash for phenol removal in aqueous systems. Am J Appl Sci 14:321-326

28. Maingi FM, Mbuvi HM, Ng'ang'a MM, Mwangi H (2018) Adsorption of cadmium ions on geopolymers derived from ordinary clay and rice husk ash. Int J Mater Chem 8(1):1-9

29. Mandal A, Mukhopadhyay P, Das SK (2018) Removal of phenol from aqueous solution using activated carbon from coconut coir. IOSR J Eng 8(12):41-55

30. Muftah HEN, Sulaiman AZ, Alhaija MA (2010) Removal of phenol from petroleum refinery wastewater through adsorption on date-pit activated carbon. Chem Eng J 162:997-1005

31. Naiya TK, Bhattacharya AK, Das SK (2009) Adsorptive removal of $\mathrm{Cd}(\mathrm{II})$ ions from aqueous solutions by rice husk ash. Environ Prog Sustain Energy 12(2009):535-546

32. Reichenberg D (1953) Properties of ion-exchange resins in relation to their structure. III. Kinetics of exchange. J Am Chem Soc 75:589-597

33. Roostaei N, Tezel FH (2004) Removal of phenol from aqueous solutions by adsorption. J Environ Manag 70:157-164

34. Shokoohi R, Jafari JA, Dargahi A, Torkshavand Z (2017) Study of the efficiency of bio-filter and activated sludge (BF/AS) combined process in phenol removal from aqueous solution: determination of removing model according to response surface methodology (RSM). Desalination Water Treat 77:256-263

35. Shokoohi R, Movahedian H, Dargahi A, Jafari AJ, Parvaresh A (2017) Survey on efficiency of BF/AS integrated biological system in phenol removal of wastewater. Desalination Water Treat 82:315-321

36. Shokoohi R, Gillani RA, Mahmoudi MM, Dargahi A (2018) Investigation of the efficiency of heterogeneous Fenton-like process using modified magnetic nanoparticles with sodium alginate in removing Bisphenol A from aquatic environments: kinetic studies. Desalination Water Treat 101:185-192

37. Singha $B$, Das SK (2012) Removal of $\mathrm{Pb}$ (II) ions from aqueous solution and industrial effluent using natural biosorbents. Environ Sci Pollut Res 19(6):2212-2226

38. Srivastava VC, Mall ID, Mishra IM (2009) Competitive adsorption of cadmium (II) and nickel (II) ions from aqueous solution onto rice husk ash. Chem Eng Process 48(1):370-379

39. Temkin MJ, Pyahev V (1940) Recent modifications of Langmuir isotherms. Acta Physiochin URRS 12:217-222

40. Uddin MT, Islam MS, Adedin MZ (2007) Adsorption of phenol from aqueous solution by water hyacinth ash. ARPN J Eng App Sci 2(2):11-17

Publisher's Note Springer Nature remains neutral with regard to jurisdictional claims in published maps and institutional affiliations. 